\title{
Renal Health: Providing Information and Technological Tools to Empower Patients to Live Better with Kidney Disease
}

\author{
Geraldo Bezerra da SILVA JUNIOR ${ }^{\mathrm{a}, 1}$, Juliana Gomes Ramalho de \\ OLIVEIRA $^{a}$, Erica Maria Rodrigues de ARAÚJO ${ }^{\mathrm{a}}$, Ana Carolina Rattacaso Marino de \\ Mattos ALBUQUERQUE ${ }^{a}$, Fabio Augusto Xerex MOTA ${ }^{a}$, Ronaldo Almeida de \\ FREITAS FILHO ${ }^{b}$, José Eurico de VASCONCELOS FILHO ${ }^{\mathrm{c}}$ and Maria Andréia \\ Formico RODRIGUES ${ }^{\mathrm{b}}$ \\ ${ }^{a}$ School of Medicine, Public Health and Medical Sciences Graduate Programs, Health \\ Sciences Center, University of Fortaleza. Fortaleza, Ceará, Brazil \\ ${ }^{\mathrm{b}}$ Applied Informatics Graduate Program, Technology Sciences Center, University of \\ Fortaleza. Fortaleza, Ceará, Brazil \\ 'Information Technology Application Nucleus, Technology Sciences Center, University \\ of Fortaleza. Fortaleza, Ceará, Brazil
}

\begin{abstract}
Chronic kidney disease (CKD) is a growing Public Health problem. Recent evidence points that low education and poor socio-economic conditions are associated with higher risk of developing CKD and progressing to dialysis or transplantation need. Hence patient empowerment through health education and qualification with technological tools that allows better treatment adherence may play an important role in the achievement of optimal clinical outcomes. The Renal Health is a multidisciplinary project created at the University of Fortaleza, northeast Brazil, in 2015, aiming to create novel educational material and technological tools for people with CKD, in different treatment modalities, including dialysis and transplant. The products developed so far in the project include an application for smartphones aiming to help patients in dialysis and transplant in their treatments, including schedule for medications, with alarms, water ingestion control, laboratory tests results, and medical appointments' agenda, besides all information regarding CKD. The other tools include a medication box, an insole for weight control (both are in the prototype phase), connection with smartbands (for vital signs monitoring) and multimedia educational tools, including a profile in the Instagram and a channel in YouTube. Since the first release of the application in the virtual stores, there were more than 1,000 downloads, predominantly in Brazil, although the app is also available in English and Spanish. All these tools represent innovative ways of patient empowerment and may be increasingly present in daily life. Further studies are required to assess the impact of these tools in patients' outcomes, including CKD progression and mortality.
\end{abstract}

Keywords. Chronic kidney disease, information technology, mobile applications, patient participation.

\footnotetext{
${ }^{1}$ Corresponding Author, Prof. Geraldo Bezerra da Silva Junior, University of Fortaleza, Public Health Graduate Program, Bloco E, Sala E-01, Av. Washington Soares, 1321, CEP 60411-905, Fortaleza, Ceará, Brazil; E-mail: geraldobezerrajr@unifor.br.
} 


\section{Introduction}

Chronic kidney disease (CKD) is a worldwide Public Health problem, which affects $9 \%$ to $14 \%$ the population and with higher incidence in disadvantaged populations [1-3]. In Brazil, CKD affects approximately $9 \%$ of the population, it predominates in blacks and people with low socio-economic conditions, and the number of patients in dialysis are growing each year at an $8 \%$ rate $[4,5]$. Adherence to treatment is crucial to achieve favorable clinical outcomes in CKD. Recent studies evidence that patients with CKD have difficulties in following the prescribed treatment, including nutritional therapy, and low adherence to treatment is associated with CKD progression and higher mortality [6, 7]. There is an urgent need to improve CKD patient care, aiming to empower patients and provide them a better quality of life. For this purpose, different initiatives have been proposed, including technological tools. A recent review has found 43 studies assessing the impact of different eHealth interventions on patients with CKD [8]. The main improvement observed with these eHealth interventions on CKD treatment was on dietary control of sodium and fluid ingestion, but the current evidence was considered to be of low quality [8]. Thus, there is an urgent need for more and better detailed research both to evaluate the impact of novel technologies on CKD patients' treatment and to increase the quality of life of this audience. The aim of this study is to present a novel strategy for empower patients with CKD using technological tools, the Renal Health project, as well as an analysis of the results achieved in the first five years since the beginning of the research project.

\section{Methods}

The Renal Health is a multidisciplinary project created at the University of Fortaleza, northeast Brazil, in 2015, aiming to create novel educational material and technological tools for people with CKD, including dialysis and kidney transplant. The first step was a study to investigate the knowledge of the population about $\mathrm{CKD}$, and there was evidence of low knowledge, as less than $30 \%$ of the interviewed people knew what is CKD [9]. The research team also had interviewed patients in dialysis and transplant to compile the information regarding their needs and about which tools would be useful to help them during renal treatment. The first product developed was an application (app) for smartphones aiming to help patients in dialysis and transplant during treatment, including schedule for medications, with alarms, water ingestion control, laboratory tests results, and medical appointments' agenda, besides all information regarding CKD. The app has also been named Renal Health and is freely available in three different languages (English, Portuguese and Spanish) in the virtual stores for devices operating on the android (https://play.google.com/store/apps/details?id=br.unifor.renalhealth) and iOS systems (https://apps.apple.com/br/app/renal-health/id1485397798\#?platform=iphone). The app has been developed by a multidisciplinary team and has already been submitted to a usability test with nephrology specialists [10]. More specifically, the analysis of information from the app was done using the Power BI desktop application (Microsoft, USA), and the data analyzed for this study was provided with the informed consent by the users, after approval by the Ethics Committee from the University of Fortaleza (protocol number 4.134.607/2020). In more detail, the Renal Health suite consists of multiple tools which have related functions, features and interfaces. These tools may be able to interact with each other and are the following: a prototype smart medicine box 
that reminds patients to take their pills and uses sensors to track the patient's progress over time, a prototype low cost system integrated into the inner soles of footwear for weight control, a vital signs monitoring through connection with smartbands, and multimedia educational tools, including an Instagram profile (https://www.instagram.com/renal_health/) and a YouTube channel (https://www.youtube.com/channel/UC3-GHeHAndcrRmbE4I_qE_w). The goals of these online and interactive platforms are to provide information for patients with CKD and for anyone interested in learning important aspects related to kidney disease, from prevention to treatment. All these information have been carefully elaborated and revised constantly by health experts, with the purpose of becoming a publicly available source of reliable kidney health information.

\section{Results}

The Renal Health application is currently in its version 2.0, with improvements done based on experts' advice and patients' feedback. Some of its main screens are shown in Figure 1.

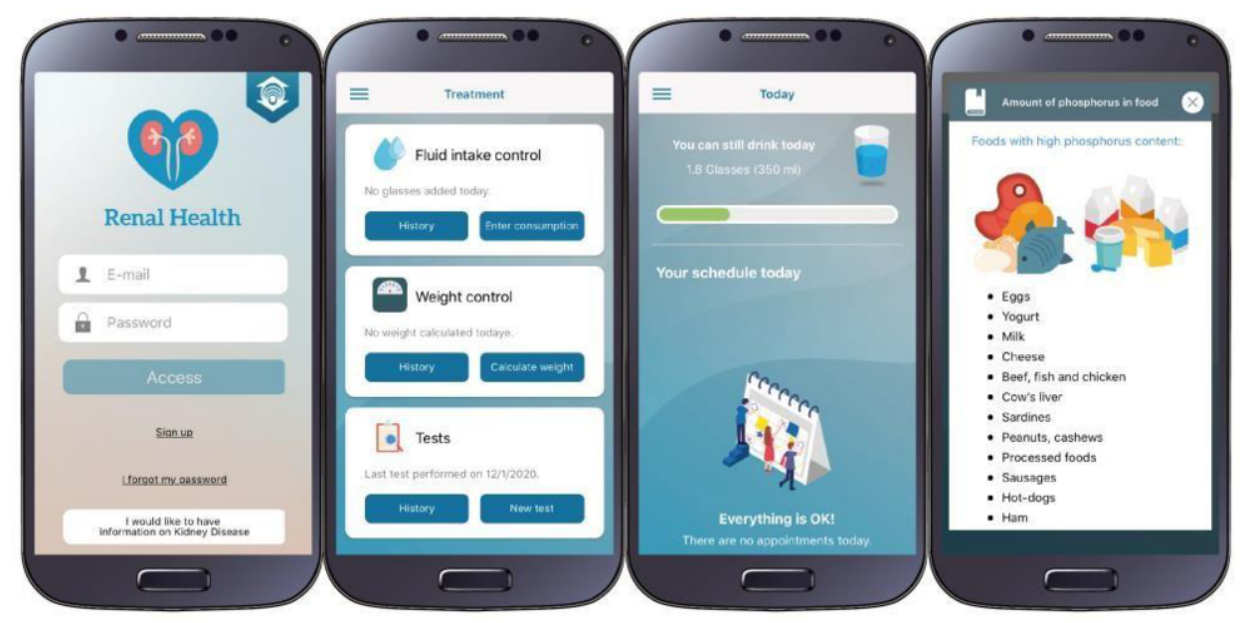

Figure 1. Main screens of the Renal Health suite.

Since the first release of the application in the virtual stores, there were more than 1,000 downloads, predominantly in Brazil. Currently, in December 2020, there are 832 users of the app, $649(78 \%)$ are patients in dialysis and $183(22 \%)$ are kidney transplant patients. The majority of patients in dialysis using the app are located in the States of São Paulo (23.7\%), Ceará (15.7\%), Minas Gerais (9.5\%) and Rio de Janeiro (9.3\%), while transplant patients are located mainly in São Paulo (22.9\%), Ceará (22.4\%), Rio de Janeiro (10.9\%) and Rio Grande do Sul (7.1\%), as shown in Figures 2 and 3. 



Figure 2. Number of patients in dialysis using the Renal Health app in Brazil, distributed by states.


Figure 3. Number of kidney transplant patients using the Renal Health app in Brazil, distributed by states.

Regarding the educational material, there are currently 6,738 Instagram followers, and 1,734 YouTube channel video views in December 2020. Moreover, there have been increasing and positive feedback from patients and interaction between the users and health professionals since the release of the material in these platforms, mainly in the Instagram.

\section{Discussion}

The Renal Health project is an innovative initiative in Brazil aiming to provide health educational for patients with $\mathrm{CKD}$, with focus on dialysis and kidney transplant, and to develop technological tools to help patients cope with their disease and facilitate treatment. It is possible that these actions can increase adherence to treatment and then decrease health complications, which still reach expressively and unacceptable high rates in CKD, including mortality [11]. The most recent data from the Global Burden of Disease study evidence CKD as the $12^{\text {th }}$ leading cause of death worldwide, leading to 1.2 million of deaths in 2017 [11]. One important strategy to decrease these numbers is empowering patients to take action, being part in their treatment, and achieve an optimal treatment adherence. All the strategies presented therein are connected and have the final purpose of ensure the best knowledge, combined with the up-to-date technological tools 
currently available on healthcare, to contribute to improved clinical outcomes of patients with CKD and kidney transplant. Finally, longitudinal studies are planned to be conducted to assess the impact of the use of these tools in clinical practice. In addition, the project also aims to refine the Renal Health suite tools, based on a tight collaboration among multi-professional healthcare teams and patients, through periodic assessment and UX testing.

\section{Acknowledgments}

We are very grateful to the International Society of Nephrology (ISN), the Edson Queiroz Foundation/University of Fortaleza and the Fundação Cearense de Apoio ao Desenvolvimento Científico e Tecnológico (FUNCAP) for the financial support given to the Renal Health project.

\section{References}

[1] GBD Chronic Kidney Disease Collaboration. Global, regional, and national burden of chronic kidney disease, 1990-2017: a systematic analysis for the Global Burden of Disease Study 2017. Lancet. 2020 Feb;395(10225):709-33.

[2] Ene-Iordache B, Perico N, Bikbov B, Carminati S, Remuzzi A, Perna A, Islam N, Bravo RF, AleckovicHalilovic M, Zou H, Zhang L, Gouda Z, Tchokhonelidze I, Abraham G, Mahdavi-Mazdeh M, Gallieni M, Codreanu I, Togtokh A, Sharma SK, Koirala P, Uprety S, Ulasi I, Remuzzi G. Chronic kidney disease and cardiovascular risk in six regions of the world (ISN-KDDC): a cross-sectional study. Lancet Glob Health. 2016 May;4(5):e307-19.

[3] Weldegiorgis M, Smith M, Herrington WG, Bankhead C, Woodward M. Socioeconomic disadvantage and the risk of advanced chronic kidney disease: results from a cohort study with 1.4 million participants. Nephrol Dial Transplant. 2020 Sep;35(9):1562-70.

[4] Barreto SM, Ladeira RM, Duncan BB, Schmidt MI, Lopes AA, Benseñor IM, Chor D, Griep RH, Vidigal PG, Ribeiro AL, Lotufo PA, Mill JG. Chronic kidney disease among adult participants of the ELSABrasil cohort: association with race and socioeconomic position. J Epidemiol Community Health. 2016;70(4):380-9.

[5] Silva AQB, Kirsztajn GM. Epidemiologia da doença renal crônica no Brasil. In: Silva Junior GB, Oliveira JGR, Barros E, Martins CTB, editors. A Nefrologia e o Sistema de Saúde do Brasil. São Paulo: Livraria Balieiro; 2019. p. 34-44.

[6] Cedillo-Couvert EA, Ricardo AC, Chen J, Cohan J, Fischer MJ, Krousel-Wood M, Kusek JW, Lederer S, Lustigova E, Ojo A, Porter AC, Sharp LK, Sondheimer J, Diamantidis C, Wang X, Roy J, Lash JP, CRIC Study Investigators. Self-reported Medication Adherence and CKD Progression. Kidney Int Rep. 2018 Feb;3(3):645-51.

[7] Lins SMSB, Leite JL, Tavares JMAB, Rocha RG, Silva FVC. Treatment adherence of chronic kidney disease patients on hemodialysis. Acta Paul Enferm. 2018 Jan/Feb;31(1):54-60.

[8] Stevenson JK, Campbell ZC, Webster AC, Chow CK, Tong A, Craig JC, Campbell KL, Lee VW. eHealth interventions for people with chronic kidney disease. Cochrane Database Syst Rev. 2019 Aug;8(8):CD012379.

[9] Silva Junior GB, Oliveira JGR, Paiva LB, Brasil BP, Pereira GA, Landim GC, Silva RML, Quintal A, Jardim MHA. Knowledge about chronic kidney disease among the general population in Brazil and Portugal. Nephrol Dial Transplant. 2019 Jun;34(Suppl. 1):i635.

[10] Oliveira JGR, Askari M, Silva Junior GB, Freitas Filho RA, Vasconcelos Filho JE. Renal Health: An Innovative Application to Increase Adherence to Treatment Through Self-monitoring for Patients With CKD and Provide Information for the General Population. Kidney Int Rep. 2019 Apr;4(4):609-13.

[11] Carney EF. The impact of chronic kidney disease on global health. Nat Rev Nephrol. 2020 May;16(5):251. 